\title{
Smell and taste dysfunction in patients with SARS-CoV-2 infection: A review of epidemiology, pathogenesis, prognosis, and treatment options
}

\author{
Jesada Kanjanaumporn, Songklot Aeumjaturapat, Kornkiat Snidvongs, Kachorn Seresirikachorn, Supinda Chusakul
}

\begin{abstract}
During the initial pandemic wave of COVID-19, apart from common presenting symptoms (cough, fever, and fatigue), many countries have reported a sudden increase in the number of smell and taste dysfunction patients. Smell dysfunction has been reported in other viral infections (parainfluenza, rhinovirus, SARS, and others), but the incidence is much lower than SARS-CoV-2 infection. The pathophysiology of post-infectious olfactory loss was hypothesized that viruses may produce an inflammatory reaction of the nasal mucosa or damage the olfactory neuroepithelium directly. However, loss of smell could be presented in COVID-19 patients without other rhinologic symptoms or significant nasal inflammation. This review aims to provide a brief overview of recent evidence for epidemiology, pathological mechanisms for the smell, and taste dysfunction in SARS-CoV-2 infected patients. Furthermore, prognosis and treatments are reviewed with scanty evidence. We also discuss the possibility of using "smell and taste loss" as a screening tool for COVID-19 and treatment options in the post-SARS-CoV- 2 infectious olfactory loss.
\end{abstract}

Key words: Smell, Taste, SAR-CoV-2, Covid-19, Olfaction

\section{From:}

Department of Otolaryngology, Faculty of Medicine,

Chulalongkorn University, Bangkok 10330, Thailand

Endoscopic Nasal and Sinus Surgery Excellence Center

King Chulalongkorn Memorial Hospital, Bangkok 10330, Thailand
Corresponding author:

Supinda Chusakul

E-mail: supinda.ent@gmail.com

\section{Introduction}

Concerning the outbreak of 2019 novel strain coronavirus, started with a cluster of unknown pneumonia patients in Wuhan, China from late December 2019, ${ }^{1}$ WHO (World Health Organization) officially announced the disease and virus names, "COVID-19 (Corona Virus Disease 2019)" and "SARS-CoV-2 (Severe Acute Respiratory Syndrome - Corona Virus 2)". Now, this pandemic (declared by WHO on March $\left.11^{\text {th }}, 2020\right)$ has rapidly spread across the world, more than 200 countries. There are multiple attempts in progress to develop the effective treatment strategies soon such as a prophylactic vaccine, monoclonal antibody therapy, and a broad-spectrum antiviral medication. ${ }^{3,4}$

Based on early reports about clinical symptoms in China, COVID-19 patients commonly presented with cough, fever, and fatigue. Less common symptoms were headache, myalgia, and shortness of breath. Upper respiratory tract symptoms such as rhinorrhea, sore throat, nasal congestion, and diarrhea were very uncommon..$^{5-9}$ Two systematic reviews also reported in the same direction that showed the frequency of clinical symptoms in COVID-19 patients: fever $83.3 \%$, cough $60.3 \%$, fatigue $38 \%$, followed by sputum, shortness of breath, myalgia (less than 30\%), and no apparent symptoms 5.6\%., ${ }^{9,10}$ There are no reports on smell/taste disorders in these studies, but the following recently preliminary shreds of evidence showed that they could be related.

However, late of March 2020, ENTUK (British Association of Otorhinolaryngology-Head and Neck Surgery ${ }^{11}$ stated that "there is good evidence that significant numbers of patients with proven COVID-19 infection have developed anosmia/ hyposmia" (Germany 2/3, South Korea 30\%). ERS (European Rhinologic Society $)^{12}$ also suggested a recommendation about "loss of smell", as a significant part of COVID-19 patient symptoms (20-60\%). Loss of smell can be the presenting symptom before others (coughing, fever, and dyspnea). Patients with sudden onset olfactory loss should be aware of COVID-19 positive. Moreover, advice not to prescribe corticosteroids (both nasal and systemic) in patients with a sudden loss of smell in the Covid-19 era has been given.

As of April 23 $3^{\text {rd }} 2020$, CDC (The Centers for Disease Control and Prevention) has now updated "new loss of taste or smell" 
to the full list of symptoms for COVID-19 (running nose and sneezing still not included) - "These symptoms of COVID-19 may appear 2-14 days after exposure to the virus: fever, cough, shortness of breath or difficulty breathing, chills, repeated shaking with chills, muscle pain, headache, sore throat, and new loss of taste or smell". ${ }^{13}$ In light of increasing confirmed evidence from many countries, recent studies are now supporting that a sudden olfactory or gustatory dysfunction could be important presenting symptoms of SARS-CoV-2 infection.

\section{Smell dysfunction in COVID-19 Importance of smell}

Olfactory dysfunction will affect the quality of life of patients. Individuals with olfactory dysfunction encounter problems with cooking, decreased appetite, personal hygiene, social relationships, and emotional problems such as depression, feeling unsafe, and feeling lonely. Women are more likely to experience emotional issues such as depression, anxiety related to olfactory impairment. ${ }^{16}$ Patients who have parosmia/ phantosmia may have more impact on their daily routine than patients with hyposmia/anosmia. The smell also has an important role in detecting warning of dangerous hazards in daily life such as gas, combustion smoke, and chemicals. ${ }^{14-16}$ (Definition of smell disorders are shown in Table 1).

Table 1. Definition of smell disorders. ${ }^{\text {modified from } 17,18}$

\begin{tabular}{|l|l|}
\hline Disorders of detection \\
\hline $\begin{array}{l}\text { Normosmia } \\
\text { Hyposmia } \\
\text { (or microsmia) }\end{array}$ & Quantitatively reduced smell function \\
\hline Anosmia & Absence of all smell function \\
\hline Hyperosmia & Hypersensitivity to common odors \\
\hline Disorders of identification (dysosmia) \\
\hline Parosmia & Altered smell perception with odor present \\
\hline Phantosmia & Perception of smell without odor present \\
\hline Cacosmia & $\begin{array}{l}\text { Perception of unpleasant smell with or without odor } \\
\text { present }\end{array}$ \\
\hline
\end{tabular}

\section{Loss of smell in COVID-19}

Although the number of olfactory dysfunction patients is recently increasing in outpatient clinics, the real prevalence and incidence in the general population are still unclear. The estimation is varied depending on definitions of dysfunction, sample areas, and assessment methods. The national surveillance system's study in South Korea, published in 2013, revealed that the prevalence of smell dysfunction was estimated at $4.5 \% .{ }^{19}$ Bhattacharyya $\mathrm{N}$ et al. ${ }^{20}$ published the prevalence of self-reported olfactory impairment in 2015, estimated at $10.6 \% \pm 1.0 \%$ of the US population in the last 12 months. It was found that the prevalence increases with age; meanwhile sex did not affect the prevalence.

Upper respiratory tract infection is one of the most common etiologies of olfactory loss, termed "post-infectious" or "post-viral" olfactory loss, accounting for up to $30-40 \%$ of the cases with olfactory loss. A variety of pathogens may cause post-infectious olfactory loss, viruses, and bacteria. However, the most common pathogen is a variety of viruses. ${ }^{18}$ Suzuki M. et al. ${ }^{21}$ reported the first study that could detect rhinovirus, parainfluenza, coronavirus, and Epstein-Barr virus in the nasal discharge of patients with post-viral olfactory loss. Furthermore, they suggested that rhinoviruses can induce a variety of severities and different time courses of olfactory loss. The pathophysiology of post-infectious olfactory loss remains poorly understood; many physicians thought about an inflammatory reaction of the nasal mucosa and the production of nasal discharge. However, many studies hypothesize that viruses may damage the olfactory neuroepithelium or central olfactory pathways and then transmit directly to the brain (including the central nervous system such as the olfactory bulb and olfactory cortex). ${ }^{18,22}$ More evidence supported this theory e.g. neuroepithelial remodeling and substitution with respiratory epithelium, and morphological alterations (decreased volumes in the olfactory bulb and olfactory cortex) in patients with post-infectious olfactory loss. ${ }^{18,23}$

ENTUK (British Association of Otorhinolaryngology-Head and Neck Surgery) ${ }^{11}$ warned doctors that evidence from many countries e.g., Italy, South Korea, and China shows that significant numbers of people with positive for COVID-19 lost the ability to smell (anosmia or hyposmia). Also, warnings for those who have a sudden loss of smell, even though they do not have other symptoms, have been issued, stating they should be self-isolated for seven days. According to a non peer-reviewed, published study from Iran, Baghari S. et al. ${ }^{24}$ reported a sudden increase in the number of olfactory dysfunction during this pandemic. Correlation between the number of olfactory disorders and confirmed COVID-19 patients was highly significant $(\mathrm{r}=0.87, P<0.001)$. Walker A et al. ${ }^{25}$ also reported a strong correlation between the frequent use of search terms related to "smell" and increases of daily confirmed COVID-19 patients (ranging from 0.633-0.952) in many pandemic countries (US, UK, Italy, Spain, Germany, France, Netherlands, and Iran). A similar study in $\operatorname{Iran}^{26}$ and the $\mathrm{UK}^{27}$ showed sudden anosmia less than one week during the mirror timing onset of the rising incidence of infected patients. These papers highly suggested that "loss of smell" should have a relationship with “COVID-19”.

A multicenter study from Europe revealed interesting data demonstrating that $85.6 \%$ of COVID-19 patients reported olfactory loss. Furthermore, this is the first study that could identify "gustatory loss"(loss of taste) as a significant clinical presentation (88.0\%) in COVID-19 patients. This paper also reported that infected patients might present isolated olfactory or gustatory loss without other significant symptoms. ${ }^{28}$ Based on another non peer-reviewed study from the UK, Menni C et al. ${ }^{29}$ assessed 1702 patients having had COVID-19 tests (579 positive and 1123 negative) and a full report on symptoms including smell and taste. Loss of smell and taste was detected in $59 \%$ of a positive COVID-19 group, but only $18 \%$ in a negative group (Odds ratio $=6.59 ; 95 \% \mathrm{CI}$ : $5.25-8.27$ ). This study also suggested that a combination of symptoms (loss of taste and smell, fever, cough, fatigue, diarrhea, abdominal pain, and loss of appetite) can be used to predict COVID-19 test positive with sensitivity (0.54) and specificity (0.86). 
A similar result was reported in the US by Yan $\mathrm{CH}$ et $\mathrm{al} .{ }^{30}$ assessing 1,480 influenza-like symptoms undergone COVID-19 testing. $68 \%$ (40 of 59 ) and $71 \%$ (42 of 59) of COVID-19 positive patients have olfactory and gustatory loss, compared to only $16 \%(33 / 203)$ and $17 \%(35 / 203)$ of negative patients. They also reported an adjusted odds ratio at 10.9 (95\%CI: 5.08-23.5) in olfactory loss and 10.2 (95\%CI: 4.74-22.1) in gustatory loss, whereas $74 \%$ (28 of 38 ) reported improving smell function with clinical resolution of disease. Kaye R. et al. ${ }^{31}$ analyzed 237 cases, which revealed that olfactory loss was presented before COVID-19 diagnosis (73\%) and was the initial symptom (26.6\%). Another recent study, Yan $\mathrm{CH}$ et al. ${ }^{32}$ demonstrated that olfactory loss was strongly associated with the mild clinical course of COVID-19 patients.

However, a non peer-reviewed study in Israel reported prevalence of only $35.7 \%$ in smell disorder and $33.3 \%$ in taste disorder. ${ }^{33}$ Regarding, two short correspondences, Benezit $\mathrm{F}$ et al. ${ }^{34}$ reported smell disorder at $45 \%(31 / 68)$ and taste disorder at $62 \%(42 / 68)$ of infected patients, and Giacomelli A et al. ${ }^{35}$ also reported smell disorder at $23.7 \%(13 / 59)$ and taste disorder at $28.8 \%$ (17/59), which are relatively less than previous studies.

In our opinion, current evidence strongly indicated that smell and taste loss is strongly associated with COVID-19. Furthermore, these symptoms should be taken into consideration when taking a history from patients suspected of COVID-19.

\section{Should we test COVID-19 in patients with isolated sudden smell disorder?}

The first report from the UK at the end of March revealed an unexplained increasing case series (11 cases) of patients presenting with isolated sudden smell disorder or isolated anosmia as a prodrome before other symptoms. However, only one case was tested for COVID-19 (with a positive result). ${ }^{36}$ According to a multicenter European study, Lechien JR et al. ${ }^{28}$ revealed that there is no significant association between olfactory dysfunction with rhinorrhea or nasal obstruction. Another related preliminary study suggested that loss of smell and taste might be a useful initial screening tool for suspected COVID-19 patients, especially when patients have both hyposmia and hypogeusia symptoms without other ENT disorders (sensitivity 42\%, specificity 95\%). ${ }^{34}$ Another short correspondence, published online in Lancet, reported that COVID-19 patients commonly present with acute onset loss of smell or taste, without any traditional nasal cavity manifestations and nasal symptoms. ${ }^{37}$ Until now, there has been inadequate evidence to conclude that we should test COVID-19 in all isolated sudden smell disorder patients. Nevertheless, healthcare physicians must be aware of patients presenting with isolated sudden smell loss as they are prone to getting SARS-CoV-2 infection.

\section{Olfactory testing (smell identification test) as a screening tool in COVID-19 patients}

At present, only one analytic study from Iran, Moein ST et al. ${ }^{38}$ assessed 60 confirmed COVID-19 patients with olfactory function tests (The University of Pennsylvania Smell Identification Test; UPSIT) and 60 controls (age and sex-matched). A very noticeable result exhibited that $98 \%$ of the patients
(59/60) have some smell dysfunction (anosmia or severe hyposmia 58\%, moderate hyposmia $33 \%$, and mild hyposmia $13 \%)$. On the contrary, only $18 \%$ of the patients in the control group had mild hyposmia (no moderate or severe hyposmia). Another interesting point is that although almost all patients have abnormal olfactory testing, only $35 \%$ of the patients $(21 / 60)$ complained about taste or smell problems. In our opinion, it can be explained that many patients are unaware of their smell loss. Accordingly, self-reported olfactory dysfunction may poorly correlate with olfactory tests e.g., smell identification. Wehling $\mathrm{E}$ et al. ${ }^{39}$ revealed that the unawareness of olfactory dysfunction (performed more poorly on cognitive tests than individuals aware of their olfactory status) in middle and old aged patients is very high (about $80 \%$ ) and also increases with older age. This evidence indicates that olfactory loss is a major clinical symptom for COVID-19, and that olfactory testing as a screening tool in some hypothetical cases to identify or quarantine can be used. However, more supporting data are still needed to confirm this suggestion.

\section{Pathological mechanisms of smell dysfunction SARS-CoV-2 and host cell entry}

Coronaviruses use its spike glycoprotein (S protein), a primary target for neutralization antibody, to bind the host receptor and mediate membrane fusion and virus entry. The critical factor of the rapidly increasing spread of COVID-19 is the high infectivity due to the extraordinary property of SARS-CoV-2 $S$ protein with much higher affinity compared to SARS-CoV, and lower thermostability factor of SARS-CoV-2. ${ }^{40-42}$ Recently, studies confirmed that SARS-CoV-2 uses the human angiotensin-converting enzyme 2 (hACE2) as the receptor for host cell entry mainly through endocytosis and uses the Transmembrane Serine Protease 2 (TMPRSS2) for S protein priming along with activation. TMPRSS2 is critical for the spread of several viruses, including influenza $\mathrm{A}$ and coronaviruses. ${ }^{41}$

Although there are discrepancies in current data, some reports showed that respiratory epithelial cells present in the nasal cavity express probably have low levels of ACE2 and TMPRSS2 proteins, compared to lower parts of the respiratory organs. ${ }^{40}$ This could be one reason that can explain why lung is the primary target organ in COVID-19.

\section{Mechanisms of sensorineural olfactory loss in COVID-19 pa- tient}

Many viruses make transient changes in odor perception because of inflammatory responses. Loss of smell (hyposmia or anosmia) has been reported in previous coronavirus infections (SARS and others), but it was quite a rare occurrence. In 2006, Hwang reported permanent anosmia case in a 27 -yearold SARS female patient. ${ }^{43}$ A recent study by Beltran-Corbellini $\mathrm{AB}$ et $\mathrm{al}^{44}$ reported significantly more frequent olfactory loss among Covid-19 patients than influenza patients. Interestingly, loss of smell could be presented in COVID-19 patients without other coryzal symptoms or significant nasal inflammation..$^{37,45,46}$ This finding is probably the reason causing 1 . the direct damage of virus on olfactory receptor neurons located in the olfactory epithelium, ${ }^{45,46} 2$. "cytokine storm" (excessive or uncontrolled production of immune cells and cytokines) initiated in some patients and affect the nervous 
system include sensory organs of smell, ${ }^{38}$ and 3 . the fact that non-neural cells located in the olfactory epithelium express both protein receptors required for efficient SARS-CoV-2 infection in humans (ACE2 and TMPRSS2). ${ }^{40}$

Nasal epithelium can be divided into respiratory epithelium and sensory olfactory epithelium, a continuously regenerating multilayer structure containing both neuronal and non-neuronal cells (Figure 1)..$^{40,46}$ Butowt $\mathrm{R}$ et al. ${ }^{40}$ reviewed studies that strongly suggest ACE2 expression in the non-neuronal olfactory epithelium but still not clear evidence to show expression in the neuronal olfactory epithelium. The expression of TMPRS2 seems to be higher compared to ACE2 and occupying both neuronal and non-neuronal cells. Brann D et al. ${ }^{46}$ showed that the whole olfactory mucosa in mouse and human species expresses two essential genes involved in SARS-CoV-2 entry,

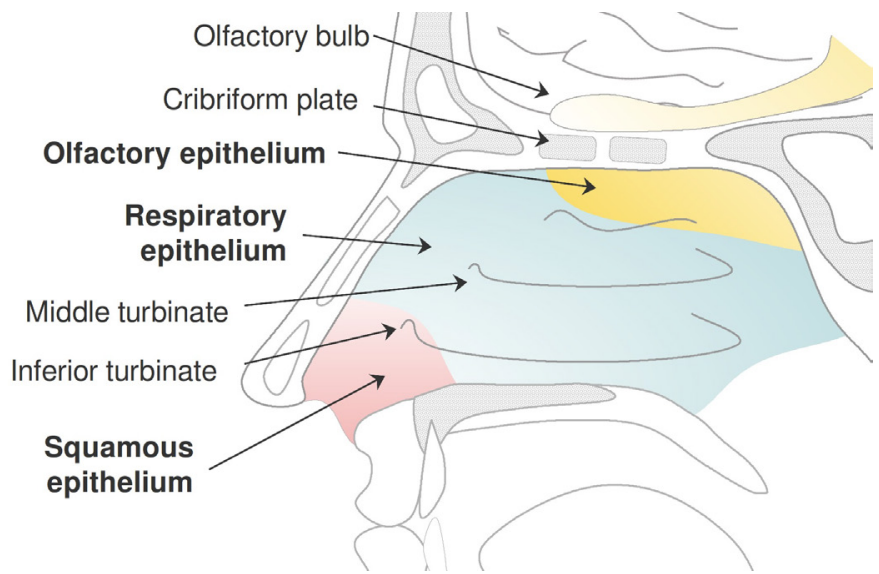

Figure 1. Schematic of a sagittal view of a human nasal cavity with olfactory, respiratory, and squamous mucosa.
ACE2, and TMPRSS2. However, neither olfactory sensory neurons nor olfactory bulb neurons display these genes, which are instead demonstrated in supporting cells, stem cells, and perivascular cells. They suggested that "virus does not directly enter olfactory sensory neurons, but instead may attack olfactory epithelium supporting and stem cells". Similarly, neurons in the olfactory bulb fail to express ACE2, whereas vascular pericytes do. They proposed that primary infection of non-neuronal cell types possibly contributes to anosmia in COVID-19 patients by " 1 . local infection of supporting cells and vascular pericytes lead to significant inflammatory responses and effects could alter the function of olfactory sensory or bulb neurons 2. supporting cells damage may indirectly influence signaling from olfactory sensory neurons to the brain 3. damage to sustentacular cells and Bowman's gland cells in mouse models leads to diffuse architectural damage to the entire olfactory epithelium, which can disturb smell function" (Figure 2).

\section{Brain entrance via the olfactory epithelium}

Neurologic manifestations in COVID-19 patients are common. Mao L. et al. ${ }^{47}$ reported that $78 / 214$ patients $(36.4 \%)$ had neurologic symptoms (central nervous system, peripheral nervous system, and skeletal muscle injury). New evidence shows that SARS-CoV-2 enters to non-neuronal olfactory cells, and it is possibly directed to the vesicular axonal pathway in neurons. Based on another hypothesis, SARS-CoV-2 may pass from non-neuronal olfactory epithelial cells directly to cerebrospinal fluid enclose the olfactory nerve bundles. After that, SARS-CoV-2 will spread to most parts of the brain, including medulla oblongata in the brain stem, a center for respiration and circulation, as shown in Figure 3. ${ }^{40}$

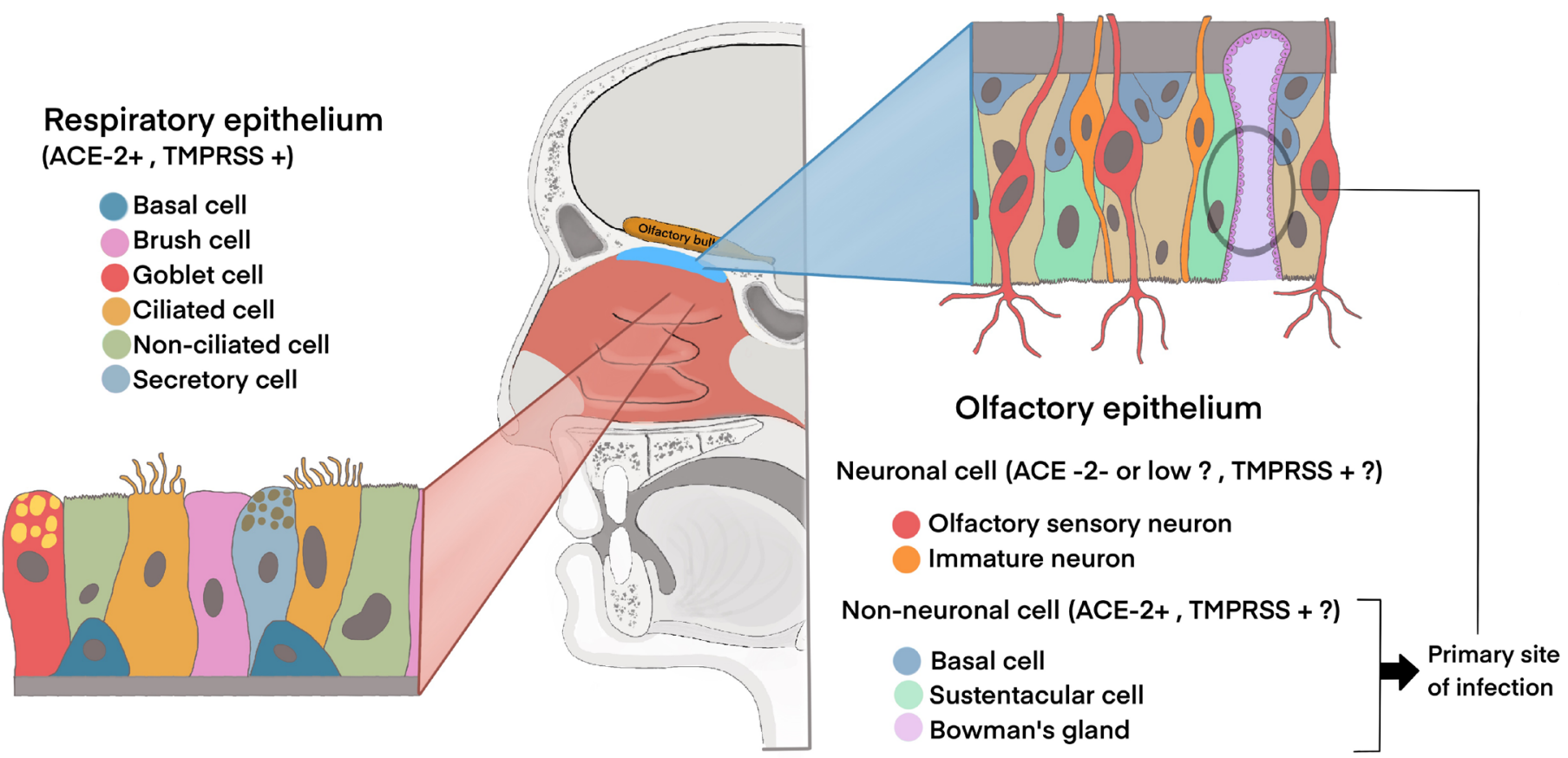

Figure 2. ${ }^{\text {modified from }}{ }^{6}$ Schematic of the basic organization of the respiratory and olfactory epithelium with the expression of ACE2 and TMPRSS (+, expression; -, no expression). Non-neuronal cells e.g., bowman's gland, sustentacular cells are the primary sites of SARS-CoV-2 infection in olfactory dysfunction patients. 


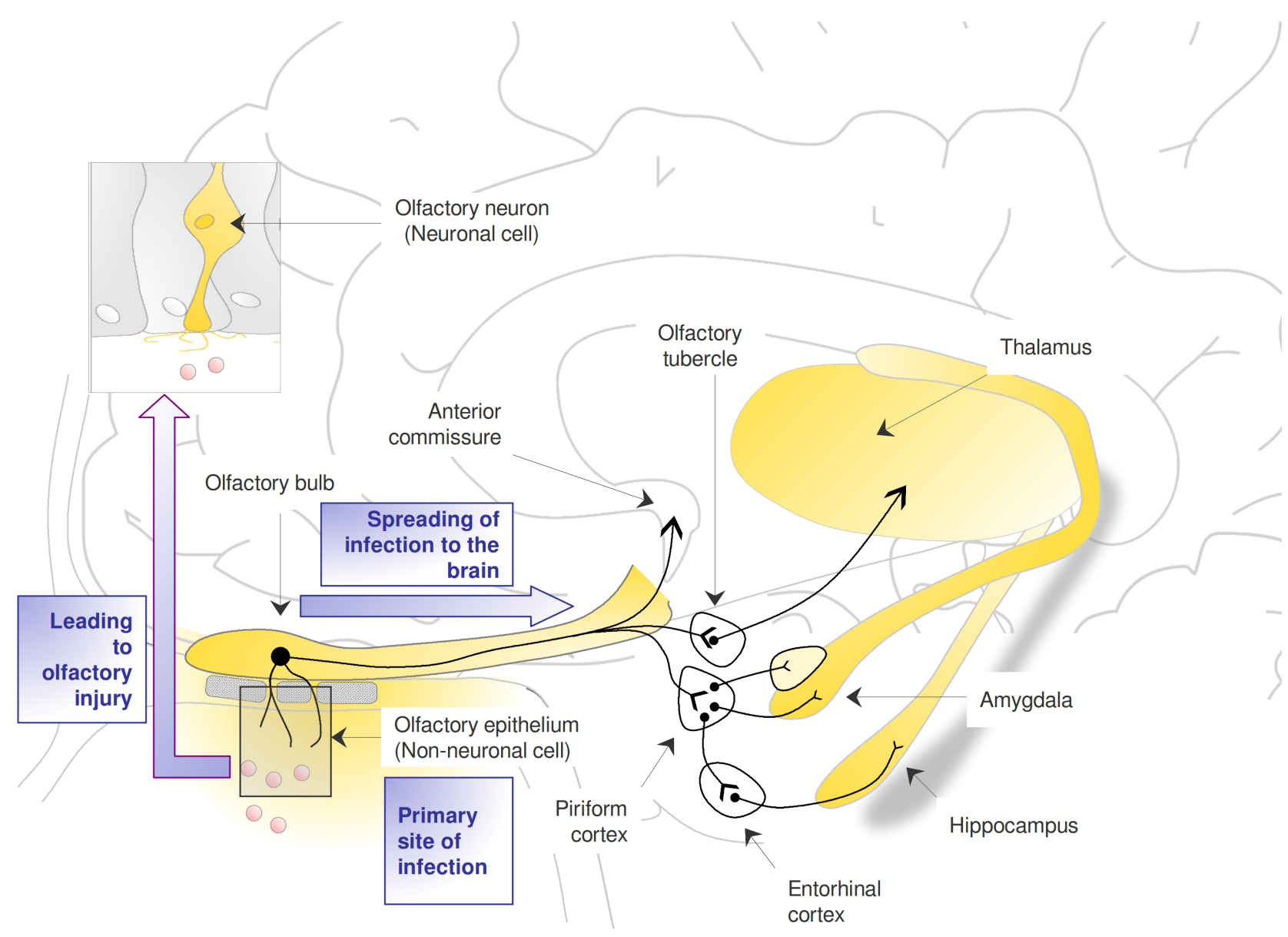

Figure 3. Neural pathway of SARS-CoV-2 infection via the olfactory epithelium.

\section{Taste dysfunction in COVID-19}

The sensation of flavor consists of the compounds including the odor's smell, taste, temperature, and texture. Each of these sensory compounds is stimulated separately to create a unique flavor when we take a meal. The overall prevalence of gustatory dysfunction is less often than that of olfactory dysfunction (Definition of taste disorders are shown in Table 2). The ability to separate flavors depends upon the retronasal stimulation pathway. Therefore, mostly "loss of taste" patients are commonly referred to retronasal olfactory dysfunction. ${ }^{18}$ However, some studies reported high ACE2 expression on

\section{Table 2. Definition of taste disorders.}

\begin{tabular}{|ll}
\hline \multicolumn{2}{l}{ Disorders of detection } \\
\hline Normogeusia & Normal taste function \\
\hline Hypogeusia & Quantitatively reduced taste function \\
Ageusia & Absence of all taste function \\
\hline
\end{tabular}

Disorders of identification (dysgeusia) $\begin{array}{ll}\text { Parageusia } & \begin{array}{l}\text { Altered taste perception (an unpleasant taste) with } \\ \text { external stimulus present }\end{array}\end{array}$

Phantogeusia

Perception of metallic or salty taste without external stimulus present the oral cavity mucosa and the epithelial cells of the tongue. In short, another possibility is that SARS-CoV-2 may have an effect on the taste buds or receptors directly (Figure 4). ${ }^{48,49}$

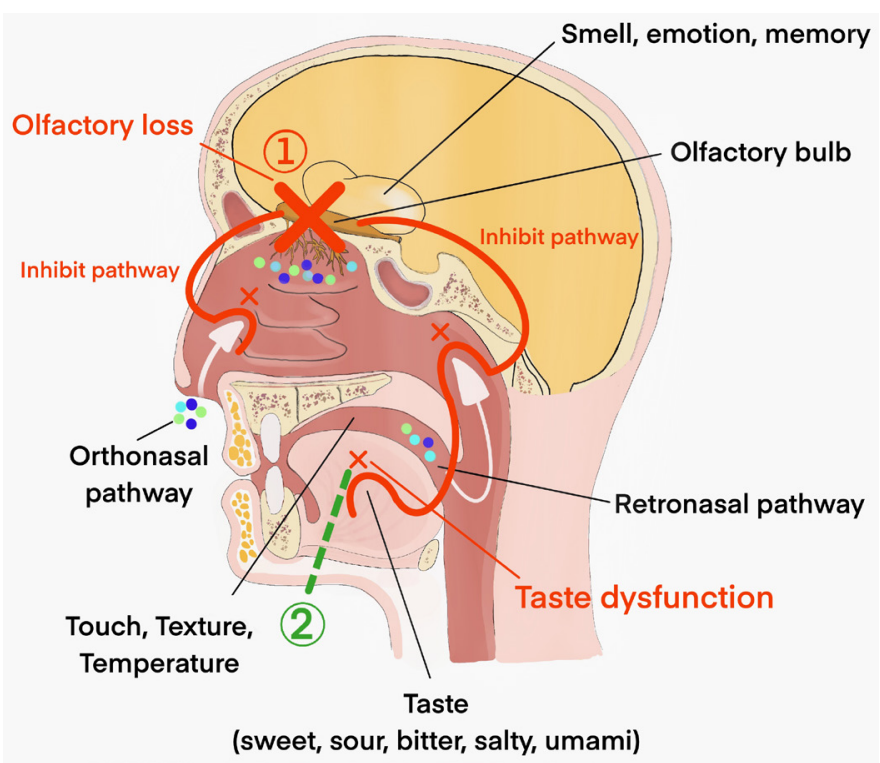

Figure 4. Hypotheses of taste dysfunction in COVID-19 (1) "Inhibit retronasal pathway" (2) "The direct effect on taste receptors". 
Not surprisingly, many studies indicated that gustatory dysfunction was reported concurrently with smell dysfunction during the SARS-CoV-2 pandemic. Lechien JR et al. ${ }^{28}$ reported gustatory disorders as high as $88.8 \%$ (308 of 342), consisting of hypogeusia/ageusia $78.9 \%$ and Parageusia $21.1 \%$. There was a significant association between smell and taste disorders. Yan $\mathrm{CH}$. et al. ${ }^{30}$ reported that $71 \%$ of COVID-19 patients (42 of 59) have gustatory dysfunction; some patients showed acute ageusia symptoms without any smell dysfunction. Other studies also revealed the results in the same way. ${ }^{33-35}$

Interestingly, it was not what we expected that prevalence of gustatory dysfunction would be higher than smell dysfunction in almost all studies. While the reasons are poorly understood and without supporting data at the time of this writing, further studies are required to explain this finding.

\section{Treatment \\ Pharmacological treatment \\ Corticosteroids}

Oral and topical corticosteroids, as the most used treatments in patients with olfactory dysfunction, have been associated with post-infection. A recent systematic review suggests that evidence is still unclear to support using these treatments. ${ }^{50}$ However, some studies argue that systemic corticosteroids can improve smell function in post-infectious olfactory dysfunction. Besides, the duration of disease, age, sex, and the presence of parosmia did not correlate with a response to corticosteroid treatment. Topical steroid treatment has been reported to improve a chance of recovery in post-infectious olfactory dysfunction patients. ${ }^{51}$ Although the interpretation of efficacy should be careful because partial or complete spontaneous recovery is about one-third of patients within a year after their infection. ${ }^{52}$

Nevertheless, The ARIA (Allergic Rhinitis and its Impact on Asthma) and EAACI (European Academy of Allergy and Clinical Immunology) mention that "prescribing local nasal spray against anosmia due to SARS-CoV-2 infection was still unanswered, and the scientific basis for this recommendation is lacking". Besides, they suggest that "intranasal corticosteroid can be continued in allergic rhinitis at the recommended dose, and stopping local intra-nasal corticosteroid is not advised for patients with COVID-19 infection". ${ }^{53}$ Moreover, ENTUK (British Association of Otorhinolaryngology-Head and Neck Surgery) recommends not to prescribe corticosteroids (both nasal and systemic) in patients with a sudden loss of smell. ${ }^{11}$
Since there is a paucity of data, prescribing corticosteroid in olfactory dysfunction due to COVID-19 is still in question and needs further evidence to support and conclude the recommendation.

\section{Other medications}

Some data report a possible benefit of other treatments such as caroverine, local injections of corticosteroid around the olfactory cleft, and alpha lipoic acid. ${ }^{50}$ More supports from large randomized controlled trials still need to make more explicit evidence. This review also investigated the use of vitamin A, minocycline, zinc sulfate, ginkgo biloba, and failed to show a statistically significant improvement. ${ }^{50}$ In contrast, Hummel $\mathrm{T}$ et al. ${ }^{54}$ revealed a benefit from intranasal vitamin $\mathrm{A}$ 10000 IU per day for two months.

Now, there is a possibility to use some medication i.e., caroverine, alpha lipoic acid, or vitamin A for treating olfactory dysfunction after Covid-19 infection. Good-quality studies need to be performed before the widespread use of these treatment regimens.

However, there is a lack of studies in treatment for olfactory dysfunction post SARS-CoV-2 infection. Based on this reason, there is no good evidence to suggest the use of these medications in the persistent smell loss post-infection.

\section{Non-pharmacological treatment Olfactory training}

"Olfactory training" is performed by patients themselves two times a day over 12 weeks, exposed to 4 intense odors (phenyl ethyl alcohol: rose, eucalyptol: eucalyptus, citronellal: lemon, and eugenol: cloves). Hummel T et al..$^{55}$ investigated olfactory loss patients due to post-infectious, posttraumatic, and idiopathic causes with this treatment. The result in the treatment group had significant improvement after a three-month course of treatment. Certain studies by Altundag A et al. ${ }^{56}$ and Konstantinidis I et al. ${ }^{57}$ investigated short and long-term olfactory training in post-infectious olfactory loss patients. These studies confirmed the efficacy of olfactory training. Increasing longer duration (up to 56 weeks) and also changing the odors can encourage a success rate of this treatment. The underlying pathophysiological mechanism for improvement after olfactory training is still uncertain. However, it is hypothesized that repeated odorant smelling might have the potential to promote the regenerative capacity of olfactory neurons. ${ }^{18}$

Table 3. Treatment options in post-infectious and post SARS-CoV-2 olfactory loss. ${ }^{50-58}$

\begin{tabular}{lll} 
Treatment options & \multicolumn{1}{c}{$\begin{array}{c}\text { Post-infectious } \\
\text { olfactory loss }\end{array}$} & \multicolumn{1}{c}{$\begin{array}{c}\text { Post SARS-CoV-2 } \\
\text { olfactory loss }\end{array}$} \\
Corticosteroids & Data still unclear & $\begin{array}{l}\text { Not recommended } \\
\text { (No studies, side effects?) }\end{array}$ \\
Intranasal & Data still unclear & $\begin{array}{l}\text { Not recommended } \\
\text { (No studies, side effects?) }\end{array}$ \\
\hline
\end{tabular}


Table 3. (Continued)

\begin{tabular}{|c|c|c|c|}
\hline Treatment options & $\begin{array}{l}\text { Post-infectious } \\
\text { olfactory loss }\end{array}$ & $\begin{array}{l}\text { Post SARS-CoV-2 } \\
\text { olfactory loss }\end{array}$ & Mechanisms \\
\hline \multicolumn{4}{|c|}{ Other pharmacological treatment } \\
\hline Intranasal vitamin $A$ & $\begin{array}{l}\text { Possible? } \\
\text { (small data) }\end{array}$ & \multirow{7}{*}{ Still not recommended (lack of studies) } & The regeneration of olfactory neurons \\
\hline Zinc & No effect & & Involved in cell proliferation, maintain the olfactory function \\
\hline Caroverine & $\begin{array}{l}\text { Possible? } \\
\text { (only } 1 \text { study) }\end{array}$ & & Reduced feedback inhibition in the olfactory bulb \\
\hline Alpha lipoic acid & $\begin{array}{l}\text { Possible? } \\
\text { (only } 1 \text { study) }\end{array}$ & & The release of nerve growth factor and antioxidative effects \\
\hline Theophylline & $\begin{array}{l}\text { Possible? } \\
\text { (small data) }\end{array}$ & & Increases the concentrations of cAMP in neurons \\
\hline Minocycline & No effect & & Anti-inflammatory and neuroprotective effects \\
\hline Ginkgo biloba & No effect? & & The antioxidative effects \\
\hline \multicolumn{4}{|l|}{ Olfactory training } \\
\hline Olfactory training & $\begin{array}{l}\text { Good effect } \\
\text { (evidence from RCT) }\end{array}$ & $\begin{array}{l}\text { No studies, but should be considered in } \\
\text { treatment option }\end{array}$ & Promote the regenerative capacity of olfactory neurons \\
\hline
\end{tabular}

At present, it is still too early to reveal the efficacy of olfactory training in COVID-19 patients with persistent olfactory loss. However, because this treatment method is related to very low cost and no serious adverse effects, it should be the first modality to be considered for treating persistent olfactory loss in COVID-19 patients before medical treatment has been proved in terms of efficacy and safety. Pharmacological and non-pharmacological treatment options are summarized in Table 3.

\section{Prognosis of smell and taste disorder after COVID-19 infection}

In post-infectious olfactory disorder, spontaneous recovery within 1-3 years is observed in the range between 32-66\% of patients. Studies have been reported to support spontaneous regeneration. ${ }^{16,52}$ Short term olfactory recovery rate in COVID-19 patients is quite a good prognosis. Data in Europe showed a recovery rate of $44 \%(72.6 \%$ recovered within the first eight days). ${ }^{28}$ Similarly, the other study in the US reported improvement at $74 \%$ of infected patients, both olfactory and taste, that correlated with overall clinical symptoms resolution.

At present, short term smell and taste recovery rate is approximately 44-74\%, which is higher than previous reports of other post-viral olfactory dysfunction such as rhinovirus, influenza, respiratory syncytial virus, and other coronaviruses. Nevertheless, it is still too early to assess long term olfactory improvement in COVID-19 patients, as well as gustatory improvement.

\section{Conclusion}

Because of the increasing confirmed pieces of evidence from many countries, recent studies are now supporting that a sudden olfactory or gustatory dysfunction could be a presenting symptom of SARS-CoV-2 infection. Pathological mechanisms are still unclear but most likely because of primary infection of non-neuronal olfactory epithelial cell types leading to olfactory neuron injuries. Characteristic symptoms of olfactory or gustatory dysfunction can be utilized to early detect COVID-19 patients and support the self-isolation process. Prognosis of smell and taste recovery in SARS-CoV-2 is better than other post-viral infection. Olfactory training may be a good option for the treatment of persistent olfactory loss.

\section{Conflict of Interest}

The authors declare no conflict of interest

\section{Acknowledgement}

The authors gratefully acknowledge Professor Kiat Ruxrungtham for his valuable suggestions and enthusiastic encouragement. We also would like to thank Sirawit Apairach for English editing, Chayut Tantrakul and Sira Vachatimanont for medical figure design.

\section{References}

1. Zhu N, Zhang D, Wang W, Li X, Yang B, Song J, et al. A Novel Coronavirus from Patients with Pneumonia in China, 2019. N Engl J Med. 2020; 382(8):727-33.

2. World health Organization. Naming the coronavirus disease (COVID-19) and the virus that causes it [Internet]; c2020 [Cited 2020 Apr 16]. Available from: https://www.who.int/emergencies/diseases/novel-coronavirus-2019/ technical-guidance/naming-the-coronavirus-disease-(covid-2019)-and -the-virus-that-causes-it

3. Prompetchara E, Ketloy C, Palaga T. Immune responses in COVID-19 and potential vaccines: Lessons learned from SARS and MERS epidemic. Asian Pac J Allergy Immunol. 2020;38(1):1-9.

4. Shanmugaraj B, Siriwattananon K, Wangkanont K, Phoolcharoen W. Perspectives on monoclonal antibody therapy as potential therapeutic intervention for Coronavirus disease-19 (COVID-19). Asian Pac J Allergy Immunol. 2020;38(1):10-8. 
5. Huang C, Wang Y, Li X, Ren L, Zhao J, Hu Y, et al. Clinical features of patients infected with 2019 novel coronavirus in Wuhan, China. The Lancet. 2020;395(10223):497-506.

6. Tan YP, Tan BY, Pan J, Wu J, Zeng SZ, Wei HY. Epidemiologic and clinical characteristics of 10 children with coronavirus disease 2019 in Changsha, China. J Clin Virol. 2020;127:104353.

7. Guan WJ, Ni ZY, Hu Y, Liang WH, Ou CQ, He JX, et al. Clinical Characteristics of Coronavirus Disease 2019 in China. N Engl J Med. 2020; 382(18): 1708-20.

8. Chen N, Zhou M, Dong X, Qu J, Gong F, Han Y, et al. Epidemiological and clinical characteristics of 99 cases of 2019 novel coronavirus pneumonia in Wuhan, China: a descriptive study. The Lancet. 2020;395(10223):507-13.

9. Fu L, Wang B, Yuan T, Chen X, Ao Y, Fitzpatrick T, et al. Clinical characteristics of coronavirus disease 2019 (COVID-19) in China: a systematic review and meta-analysis. J Infect. 2020;S0163-4453(20) 30170-5.

10. Lovato A, de Filippis C. Clinical Presentation of COVID-19: A Systematic Review Focusing on Upper Airway Symptoms. Ear Nose Throat J. 2020: 145561320920762 .

11. British Association of Otorhinolaryngology - Head and Neck Surgery. Loss of sense of smell as marker of COVID-19 infection [Internet]; c2020 [Cited 2020 Apr 17]. Available from: https://www.entuk.org/sites/default/ files/files/Loss\%20of\%20sense\%20of\%20smell\%20as\%20marker\%20of\%20 COVID.pdf

12. European Rhinologic Society. Loss of smell [Internet] ; c2020 [Cited 2020 Apr 17]. Available from: https://www.europeanrhinologicsociety.org/? page_id=2143

13. The Centers for Disease Control and Prevention. Symptoms of Coronavirus [Internet]; c2020 [Cited 2020 Apr 27]. Available from: https://www.cdc.gov/ coronavirus/2019-ncov/symptoms-testing/symptoms.html

14. Temmel AF, Quint C, Schickinger-Fischer B, Klimek L, Stoller E, Hummel T. Characteristics of olfactory disorders in relation to major causes of olfactory loss. Arch Otolaryngol Head Neck Surg. 2002;128(6):635-41.

15. Kollndorfer K, Reichert JL, Bruckler B, Hinterleitner V, Schopf V. Self-esteem as an important factor in quality of life and depressive symptoms in anosmia: A pilot study. Clin Otolaryngol. 2017;42(6): 1229-34.

16. Boesveldt S, Postma EM, Boak D, Welge-Luessen A, Schopf V, Mainland JD, et al. Anosmia-A Clinical Review. Chem Senses. 2017;42(7):513-23.

17. Holbrook EH, Leopold DA. An updated review of clinical olfaction. Curr Opin Otolaryngol Head Neck Surg. 2006;14(1):23-8.

18. Hummel T, Whitcroft KL, Andrews P, Altundag A, Cinghi C, Costanzo RM, et al. Position paper on olfactory dysfunction. Rhinol Suppl. 2017;54(26): $1-30$.

19. Lee WH, Wee JH, Kim DK, Rhee CS, Lee CH, Ahn S, et al. Prevalence of subjective olfactory dysfunction and its risk factors: korean national health and nutrition examination survey. PLoS One. 2013;8(5):e62725.

20. Bhattacharyya N, Kepnes LJ. Contemporary assessment of the prevalence of smell and taste problems in adults. Laryngoscope. 2015;125(5):1102-6.

21. Suzuki M, Saito K, Min WP, Vladau C, Toida K, Itoh H, et al. Identification of viruses in patients with postviral olfactory dysfunction. Laryngoscope. 2007;117(2):272-7.

22. Youngentob SL, Schwob JE, Saha S, Manglapus G, Jubelt B. Functional consequences following infection of the olfactory system by intranasal infusion of the olfactory bulb line variant (OBLV) of mouse hepatitis strain JHM. Chem Senses. 2001;26(8):953-63.

23. Yao L, Yi X, Pinto JM, Yuan X, Guo Y, Liu Y, et al. Olfactory cortex and Olfactory bulb volume alterations in patients with post-infectious Olfactory loss. Brain Imaging Behav. 2018;12(5):1355-62.

24. Bagheri S, Asghari A, Farhadi M, Shamshiri A, Kabir A, Kamrava S, et al. Coincidence of COVID-19 epidemic and olfactory dysfunction outbreak. 2020

25. Walker A, Hopkins C, Surda P. The use of google trends to investigate the loss of smell related searches during COVID-19 outbreak. Int Forum Allergy Rhinol. 2020.

26. Gilani S, Roditi R, Naraghi M. COVID-19 and anosmia in Tehran, Iran. Med Hypotheses. 2020;141:109757.

27. Hopkins C, Surda P, Kumar N. Presentation of new onset anosmia during the COVID-19 pandemic. Rhinology. 2020; Apr 11. doi: 10.4193/ Rhin20.116.[Epub ahead of print]
28. Lechien JR, Chiesa-Estomba CM, De Siati DR, Horoi M, Le Bon SD, Rodriguez A, et al. Olfactory and gustatory dysfunctions as a clinical presentation of mild-to-moderate forms of the coronavirus disease (COVID-19): a multicenter European study. Eur Arch Otorhinolaryngol. 2020;1-11.

29. Menni C, Valdes A, Freydin MB, Ganesh S, El-Sayed Moustafa J, Visconti A et al. Loss of smell and taste in combination with other symptoms is a strong predictor of COVID-19 infection. medRxiv. 2020:2020.04.05.20048421.

30. Yan CH, Faraji F, Prajapati DP, Boone CE, DeConde AS. Association of chemosensory dysfunction and Covid-19 in patients presenting with influenza-like symptoms. Int Forum Allergy Rhinol. 2020; Apr 12. doi: 10.1002/alr.22579. [Epub ahead of print]

31. Kaye R, Chang D, Kazahaya K, Brereton J, Denneny J. COVID-19 Anosmia Reporting Tool: Initial Findings. Otolaryngology-Head and Neck Surgery. 2020; Apr 28. doi.org/10.1177/0194599820922992. [Epub ahead of print]

32. Yan CH, Faraji F, Prajapati DP, Ostrander BT, DeConde AS. Self-reported olfactory loss associates with outpatient clinical course in Covid-19. Int Forum Allergy Rhinol. 2020; Apr 24. doi: 10.1002/alr.22592. [Epub ahead of print]

33. Levinson R, Elbaz M, Ben-Ami R, Shasha D, Levinson T, Choshen G, et al. Anosmia and dysgeusia in patients with mild SARS-CoV-2 infection. medRxiv. 2020:2020.04.11.20055483.

34. Benezit F, Le Turnier P, Declerck C, Paille C, Revest M, Dubee V, et al Utility of hyposmia and hypogeusia for the diagnosis of COVID-19. Lancet Infect Dis. 2020; Apr 15. doi: 10.1016/S1473-3099(20)30297-8. [Epub ahead of print]

35. Giacomelli A, Pezzati L, Conti F, Bernacchia D, Siano M, Oreni L, et al Self-reported olfactory and taste disorders in SARS-CoV-2 patients: a cross-sectional study. Clin Infect Dis. 2020; Mar 26;ciaa330. doi: 10.1093/ $\mathrm{cid} / \mathrm{ciaa330}$. [Epub ahead of print]

36. Gane SB, Kelly C, Hopkins C. Isolated sudden onset anosmia in COVID-19 infection. A novel syndrome? Rhinology. 2020; Apr 2. doi: 10.4193/ Rhin20.114. [Epub ahead of print]

37. Xydakis MS, Dehgani-Mobaraki P, Holbrook EH, Geisthoff UW, Bauer C Hautefort C, et al. Smell and taste dysfunction in patients with COVID-19. Lancet Infect Dis. 2020; Apr 15. doi: 10.1016/S1473-3099(20)30293-0. [Epub ahead of print]

38. Moein ST, Hashemian SMR, Mansourafshar B, Khorram-Tousi A, Tabarsi P, Doty RL. Smell dysfunction: a biomarker for COVID-19. Int Forum Allergy Rhinol. 2020; Apr 17. doi: 10.1002/alr.22587. [Epub ahead of print]

39. Wehling E, Nordin S, Espeseth T, Reinvang I, Lundervold AJ. Unawareness of olfactory dysfunction and its association with cognitive functioning in middle aged and old adults. Arch Clin Neuropsychol. 2011;26(3):260-9.

40. Butowt R, Bilinska K. SARS-CoV-2: Olfaction, Brain Infection, and the Urgent Need for Clinical Samples Allowing Earlier Virus Detection. ACS Chem Neurosci. 2020; 11(9): 1200-3.

41. Hoffmann M, Kleine-Weber H, Schroeder S, Kruger N, Herrler T, Erichsen S, et al. SARS-CoV-2 Cell Entry Depends on ACE2 and TMPRSS2 and Is Blocked by a Clinically Proven Protease Inhibitor. Cell. 2020;181(2):271-80. e8.

42. Ou X, Liu Y, Lei X, Li P, Mi D, Ren L, et al. Characterization of spike glycoprotein of SARS-CoV-2 on virus entry and its immune cross-reactivity with SARS-CoV. Nat Commun. 2020;11(1):1620.

43. Hwang CS. Olfactory neuropathy in severe acute respiratory syndrome: report of A case. Acta Neurol Taiwan. 2006;15(1):26-8.

44. Beltran-Corbellini A, Chico-Garcia JL, Martinez-Poles J, Rodriguez-Jorge F, Natera-Villalba E, Gomez-Corral J, et al. Acute-onset smell and taste disorders in the context of Covid-19: a pilot multicenter PCR-based case-control study. Eur J Neurol. 2020; Apr 22. doi: 10.1111/ene.14273. [Epub ahead of print]

45. Vaira LA, Salzano G, Deiana G, De Riu G. Anosmia and Ageusia: Common Findings in COVID-19 Patients. Laryngoscope. 2020; Apr 1. doi: 10.1002/ lary.28692. [Epub ahead of print]

46. Brann D, Tsukahara T, Weinreb C, Lipovsek M, Berge K, Gong B, et al Non-neural expression of SARSCoV-2 entry genes in the olfactory system suggests mechanisms underlying COVID-19-associated anosmia. BioRxiv [Preprint]. 2020[cited 2020 Apr 30]. Available from: https://www.biorxiv. org/content/10.1101/2020.03.25.009084v3

47. Mao L, Jin H, Wang M, Hu Y, Chen S, He Q, et al. Neurologic Manifestations of Hospitalized Patients With Coronavirus Disease 2019 in Wuhan, China. JAMA Neurol. 2020; Apr 10. doi:10.1001/jamaneurol.2020.1127. [Epub ahead of print] 
48. Xu H, Zhong L, Deng J, Peng J, Dan H, Zeng X, et al. High expression of ACE2 receptor of 2019-nCoV on the epithelial cells of oral mucosa. Int J Oral Sci. 2020;12(1).

49. Vaira LA, Salzano G, Fois AG, Piombino P, De Riu G. Potential pathogenesis of ageusia and anosmia in COVID-19 patients. Int Forum Allergy Rhinol. 2020; Apr 27. doi: 10.1002/alr.22593. [Epub ahead of print]

50. Harless L, Liang J. Pharmacologic treatment for postviral olfactory dysfunction: a systematic review. Int Forum Allergy Rhinol. 2016;6(7): 760-7.

51. Scangas GA, Bleier BS. Anosmia: Differential diagnosis, evaluation, and management. Am J Rhinol Allergy. 2017;31(1):3-7.

52. Daramola OO, Becker SS. An algorithmic approach to the evaluation and treatment of olfactory disorders. Curr Opin Otolaryngol Head Neck Surg. 2015;23(1):8-14.

53. Bousquet J, Akdis C, Jutel M, Bachert C, Klimek L, Agache I, et al. Intranasal corticosteroids in allergic rhinitis in COVID-19 infected patients: An ARIA-EAACI statement. Allergy. 2020; Mar 31. doi: 10.1111/ all.14302. [Epub ahead of print]
54. Hummel T, Whitcroft KL, Rueter G, Haehner A. Intranasal vitamin A is beneficial in post-infectious olfactory loss. Eur Arch Otorhinolaryngol. 2017;274(7):2819-25.

55. Hummel T, Rissom K, Reden J, Hahner A, Weidenbecher M, Huttenbrink KB. Effects of olfactory training in patients with olfactory loss. Laryngoscope. 2009;119(3):496-9.

56. Altundag A, Cayonu M, Kayabasoglu G, Salihoglu M, Tekeli H, Saglam O, et al. Modified olfactory training in patients with postinfectious olfactory loss. Laryngoscope. 2015;125(8):1763-6.

57. Konstantinidis I, Tsakiropoulou E, Constantinidis J. Long term effects of olfactory training in patients with post-infectious olfactory loss. Rhinology. 2016;54(2):170-5.

58. Soter A, Kim J, Jackman A, Tourbier I, Kaul A, Doty RL. Accuracy of self-report in detecting taste dysfunction. Laryngoscope. 2008;118(4): 611-7. 